\title{
Mutagenic Analysis of the Roles of SH2 and SH3 Domains in Regulation of the Abl Tyrosine Kinase
}

\author{
BRUCE J. MAYER $\dagger$ AND DAVID BALTIMORE* \\ The Rockefeller University, New York, New York 10021
}

Received 22 November 1993/Returned for modification 3 January 1994/Accepted 25 January 1994

\begin{abstract}
We have used in vitro mutagenesis to examine in detail the roles of two modular protein domains, $\mathrm{SH} 2$ and SH3, in the regulation of the Abl tyrosine kinase. As previously shown, the SH3 domain suppresses an intrinsic transforming activity of the normally nontransforming c-Abl product in vivo. We show here that this inhibitory activity is extremely position sensitive, because mutants in which the position of the SH3 domain within the protein is subtly altered are fully transforming. In contrast to the case in vivo, the SH3 domain has no effect on the in vitro kinase activity of the purified protein. These results are consistent with a model in which the SH3 domain binds a cellular inhibitory factor, which in turn must physically interact with other parts of the kinase. Unlike the SH3 domain, the SH2 domain is required for transforming activity of activated Abl alleles. We demonstrate that SH2 domains from other proteins (Ras-GTPase-activating protein, Src, p85 phosphatidylinositol 3-kinase subunit, and Crk) can complement the absence of the Abl SH2 domain and that mutants with heterologous SH2 domains induce altered patterns of tyrosine-phosphorylated proteins in vivo. The positive function of the $\mathrm{SH} 2$ domain is relatively position independent, and the effect of multiple SH2 domains appears to be additive. These results suggest a novel mechanism for regulation of tyrosine kinases in which the SH2 domain binds to, and thereby enhances the phosphorylation of, a subset of proteins phosphorylated by the catalytic domain. Our data also suggest that the roles of the $\mathrm{SH} 2$ and $\mathrm{SH} 3$ domains in the regulation of Abl are different in several respects from the roles proposed for these domains in the closely related Src family of tyrosine kinases.
\end{abstract}

Protein-tyrosine kinases play a central role in the regulation of cellular growth and differentiation of complex eukaryotes. The two major classes of tyrosine kinases are the transmembrane receptors, which are activated directly by binding of peptide growth factors and cytokines to their extracellular domains, and the nonreceptor kinases (for reviews, see references 5, 13, and 46). While the normal function of the receptors as transducers of extracellular signals is evident, the role of nonreceptor tyrosine kinases is in many cases unknown. Examples of both classes of kinases have been shown to function as dominant oncogenes, generally as a result of overexpression and structural alteration (see reference 14 for a review).

The Abl nonreceptor tyrosine kinase was originally isolated as the transforming gene of Abelson murine leukemia virus (12) and was subsequently shown to be involved in human leukemias by virtue of a chromosomal translocation resulting in the expression of a fusion protein containing $\mathrm{N}$-terminal sequences from a second locus, $b c r(28,48)$. Overexpression of c-Abl does not result in efficient cell transformation or elevated tyrosine phosphorylation in vivo $(10,15)$, whereas structurally altered forms are able to efficiently induce transformation and elevated phosphotyrosine in a variety of cell types, suggesting that the activity of the normal kinase is tightly regulated. As in the Src family of tyrosine kinases, $\mathrm{N}$ terminal to the catalytic domain of $\mathrm{Abl}$ are two small modular domains termed the Src homology 2 and 3 (SH2 and SH3) domains. Previous work in a number of laboratories has suggested that

\footnotetext{
* Corresponding author. Mailing address: The Rockefeller University, 1230 York Ave., New York, NY 10021. Phone: (212) 327-8957.

$\uparrow$ Present address: Howard Hughes Medical Institute, Children's Hospital, Boston, MA 02115.
}

the $\mathrm{SH} 2$ and $\mathrm{SH} 3$ domains of nonreceptor tyrosine kinases are involved in regulation of kinase activity in vivo.

$\mathrm{SH} 2$ and SH3 domains are found in a wide variety of proteins and are thought to function by mediating controlled protein-protein interactions (reviewed in references 24 and 34). SH3 domains are implicated in the repression of activity of $\mathrm{Abl}$ and the Src family kinases, because deletion or mutation of this domain generally activates the transforming activity of the proto-oncogenes $(10,15,17,39)$. Several SH3 domain-binding proteins have now been isolated, and a proline-rich binding motif for the Abl SH3 domain has been identified $(4,41)$. SH2 domains have been shown to bind specifically and with high affinity to tyrosine-phosphorylated proteins (1a, 20, 23, 25, 30) and are thought to mediate the association of signaling proteins in response to tyrosine phosphorylation. We have previously shown that activated Abl proteins with mutated $\mathrm{SH} 2$ domains that are no longer able to efficiently bind tyrosinephosphorylated proteins are impaired in their ability to transform (26).

We have devised a mutagenesis scheme that facilitates the deletion, reiteration, swapping, and movement within the protein of various modular domains of the Abl tyrosine kinase. These mutants have been used to examine in detail the roles of the $\mathrm{SH} 2$ and $\mathrm{SH} 3$ domains in the regulation of Abl activity. As expected from previous results, we find that the $\mathrm{SH} 2$ and $\mathrm{SH} 3$ domains play very different roles: the $\mathrm{SH} 3$ domain appears to suppress the intrinsic transforming ability of Abl, while the $\mathrm{SH} 2$ is absolutely required for expression of the transforming activity of activated Abl genes. We extend these observations to show that in cells, the inhibitory activity of the SH3 domain is extremely sensitive to its position in the Abl molecule, but its presence or absence has no effect on the in vitro kinase activity of the purified protein, suggesting that the $\mathrm{SH} 3$ domain regulates kinase activity in vivo by a complex mechanism. We 
also find that the $\mathrm{SH} 2$ domain, not the catalytic domain, is largely responsible for determining the spectrum of proteins phosphorylated in vivo. We propose that the $\mathrm{SH} 2$ domain is required for transforming activity because it modulates the output of a relatively nonspecific catalytic domain by directly binding to, and enhancing the phosphorylation of, a subset of proteins phosphorylated by the catalytic domain.

\section{MATERIALS AND METHODS}

Construction of Abl Mutants. All Abl genes were constructed from modular fragments generated by PCR using wild-type murine type IV c-Abl cDNA (pPLcIV) $(2,15)$ and primers encoding unique restriction sites on their $5^{\prime}$ ends. $P f u$ DNA polymerase (Stratagene) was used as recommended by the manufacturer except that elongation times were occasionally extended to $5 \mathrm{~min}$ to generate longer fragments. PCR primers had 24 to 30 nucleotides (nt) of identity with template, 6 or $8 \mathrm{nt}$ encoding restriction sites, and five or six $\mathrm{G}$ or $\mathrm{C}$ residues $5^{\prime}$ to clamp the ends of the fragment to facilitate restriction digestion. All PCR fragments were sequenced to approximately $200 \mathrm{nt}$ from each end; no mutations were observed in any clone except in regions of primer binding. Only clones of the expected sequence were used for further studies.

The prototype modular c-Abl gene (termed construct F) consisted of three PCR fragments (all nucleotide numbers are relative to the $A$ of the initiation codon of murine type IV c-Abl): N-terminal fragment A (NotI, nt -9 to 252, SacII), SH3-plus-SH2 fragment F (SacII, nt 256 to 723, Bam HI), and catalytic domain-plus-C-terminus fragment B (BamHI, nt 730 to $3465, N o t \mathrm{I})$. Deletions of $\mathrm{SH} 2$ or $\mathrm{SH} 3$ were generated by replacing fragment F with fragment E (SacII, nt 256 to 417, Bam HI) or fragment G (SacII, nt 427 to 723 , Bam HI), to generate constructs $E$ and $G$, respectively; deletion of both was effected by replacing fragment $F$ with a short synthetic adaptor (top strand, 5' TCGCGAACA; bottom strand, 5' GATCTGT TCGCGAGC) to generate construct 9. For constructs with $\mathrm{SH} 2$ and/or SH3 domains $\mathrm{C}$ terminal to the catalytic domain, two other fragments were generated using construct 9 DNA as the template: $\mathrm{N}$-terminal and catalytic domain fragment $\mathrm{C}$ (NotI, nt -9 to 1620, SacII) and C-terminal fragment D (BamHI, nt 1621 to 3465 , NotI).

All constructs were initially manipulated while cloned into a modified vector derived from $\mathrm{pBS}-\mathrm{SK}(-)$ (Stratagene), termed $\mathrm{pBS} \Delta$, in which the vector SacII and BamHI sites had been destroyed. For virus production, NotI Abl fragments were cloned into pGDN, a derivative of the retroviral vector pGD (7) in which the XhoI cloning site had been converted to a unique NotI site. All constructs were derived from the same cloned PCR fragments A, B, C, D, E, F, and G so that there could be no clone-to clone variation due to $P f u$ polymerase errors. Further details of the construction of all mutants described here can be provided on request.

For mutants in which portions of Abl are swapped with heterologous $\mathrm{SH} 2$ or catalytic domains, fragments were generated by PCR as described above with appropriate restriction sites. All SH2 domains contained 5' SacII and 3' BamHI sites and consisted of the following amino acids: murine $\mathrm{N}$-terminal GTPase-activating protein (GAP) SH2 domain, corresponding to amino acids (aa) 178 to 274 of human GAP (52); murine Src $\mathrm{SH} 2$ domain, aa 153 to 255 of neuronal form (21); murine p85 phosphatidylinositol (PI) 3-kinase subunit C-terminal SH2 domain, aa 618 to 720 (8); and chicken c-Crk SH2 domain, aa 7 to 121 (40). The Src catalytic domain consisted of aa 249 to 524 of chicken c-Src (corresponding to aa 257 to 532 of murine neuronal form [21]), with 5' Bam HI and 3' BglII sites. This was ligated to the NotI-Bam HI N-terminal-plus-SH2 domain fragments containing various $\mathrm{SH} 2$ domains and the Bam HI-NotI C-terminal D fragment to generate the GSC series of mutants.

Generation of virus and assay of biological activity. Infectious virus expressing various $\mathrm{Abl}$ genes was produced by transient transfection of 293 cells. Generally 2 to $5 \mu \mathrm{g}$ of pGDN-derived plasmid and 2 to $5 \mu \mathrm{g}$ of pZAP, which encodes intact Moloney murine leukemia virus (15), were introduced by calcium phosphate coprecipitation into $4 \times 10^{6} 293$ cells in a 10-cm-diameter plate. In some experiments, chloroquine was added to $25 \mu \mathrm{M}$ just prior to transfection. The medium was changed after approximately $8 \mathrm{~h}$, and virus stocks were collected 2 days later. 293 cells were cultured in Dulbecco's modified Eagle's medium supplemented with $10 \%$ fetal calf serum and antibiotics.

Focus assays and G418-resistant colony assays were determined on NIH 3T3 cells. Only early-passage cells of a subclone chosen for flat morphology were used to assay transformation. 3T3 cells were maintained in Dulbecco's modified Eagle's medium supplemented with $10 \%$ donor calf serum plus antibiotics. Six-centimeter-diameter dishes seeded with approximately $10^{5}$ cells were infected with $1 \mathrm{ml}$ of diluted virus and 1 $\mathrm{ml}$ of medium supplemented with $16 \mu \mathrm{g}$ of Polybrene per ml. Virus was removed after $8 \mathrm{~h}$ and replaced with fresh medium. To select G418-resistant colonies, medium was changed to medium containing $1 \mathrm{mg}$ of G418 per $\mathrm{ml}$ the next day. All plates were fed at 3-day intervals thereafter. Morphologically altered foci were scored 7 to 10 days postinfection, and G418-resistant colonies were scored 10 to 14 days postinfection.

Transient infections and protein characterization. For analysis of tyrosine-phosphorylated proteins induced by $\mathrm{Abl} \mathrm{SH} 2$ domain mutants, $2.5 \times 10^{5} 3 \mathrm{~T} 3$ cells were infected in $10-\mathrm{cm}$ diameter dishes with $4 \mathrm{ml}$ of undiluted virus stocks (multiplicity of infection of $\sim 1$ ). Two days postinfection, cells were lysed in $0.5 \mathrm{ml}$ of Triton extraction buffer (TXB; $10 \mathrm{mM}$ Tris [pH 7.4], $150 \mathrm{mM} \mathrm{NaCl}, 5 \mathrm{mM} \mathrm{Na}{ }_{2}$ EDTA, $10 \%$ glycerol, $1 \%$ Triton $\mathrm{X}-100,1 \mathrm{mM} \mathrm{Na} \mathrm{VO}_{4}, 1 \mathrm{mM}$ phenylmethylsulfonyl fluoride, $20 \mu \mathrm{g}$ of aprotinin per $\mathrm{ml}$ ) on ice for $30 \mathrm{~min}$ and centrifuged for $10 \mathrm{~min}$ in a microcentrifuge to clear, and protein concentrations were assayed by the Bradford method (Bio-Rad). For immunoblotting, equal amounts of cell protein were separated on sodium dodecyl sulfate (SDS)-polyacrylamide gels and transferred to nitrocellulose in $10 \mathrm{mM}$ CAPS ( $\mathrm{pH}$ 11)-20\% methanol for $2 \mathrm{~h}$ at $500 \mathrm{~mA}$. Filters were blocked in TBST $(10$ $\mathrm{mM}$ Tris [pH 8.0], $0.9 \% \mathrm{NaCl}, 0.05 \%$ Tween 20 ) with $1 \%$ ovalbumin and $0.02 \% \mathrm{NaN}_{3}$ for several hours at $4^{\circ} \mathrm{C}$ and then incubated overnight at $4^{\circ} \mathrm{C}$ in blocking buffer containing either a combination of monoclonal antibodies 4G10 (Upstate Biochemical, Inc.) and PY20 (11) (for antiphosphotyrosine blotting) or affinity-purified rabbit polyclonal antibody directed against the Abl type IV-specific N-terminal sequences. After washing with TBST, filters were incubated with alkaline phosphatase-conjugated donkey anti-mouse immunoglobulin (for antiphosphotyrosine blotting) or either alkaline phosphataseconjugated protein A or alkaline phosphatase-conjugated donkey anti-rabbit immunoglobulin, washed again, and developed with nitroblue tetrazolium and 5-bromo-4-chloro-3-indolylphosphate toluidinium.

For anti-Abl immunoprecipitations, equal amounts of cell protein were incubated on ice with crude Abl-specific pEX-4 serum (19). Immunoprecipitates were collected on protein A-Sepharose beads, washed three times with lysis buffer, resuspended in sample buffer, boiled, and separated on SDSpolyacrylamide gels. For antiphosphotyrosine immunoprecipitates, Affi-Gel-Hz beads (Bio-Rad) were covalently coupled 
to phosphotyrosine-specific monoclonal antibody PY20 for a final concentration of $2.5 \mathrm{mg}$ of immunoglobulin per $\mathrm{ml}$ of beads, following the manufacturer's recommendations. Equal amounts of cell protein were incubated on ice with PY20 beads and then washed, electrophoresed, and immunoblotted as described above.

Production and characterization of GST-Abl fusion proteins. The glutathione $S$-transferase (GST) fragment from pGEX-2T (49) was modified by PCR so that the initiation codon was preceded by a eukaryotic Kozak consensus ribosome binding site and a $5^{\prime}$ BglII site. The BglII-BamHI 0.7-kb fragment so generated was cloned into the unique $B a m \mathrm{HI}$ site of baculovirus vector pVL1393 (Invitrogen, Inc.) to generate plasmid pVLGS. The Abl genes of construct E, F, and G described above were inserted into pVLGS. To do this, an alternative $\mathrm{N}$-terminal fragment $\mathrm{A}$ was synthesized by PCR, consisting of BamHI, nt 4 to 252, SacII. This fragment was ligated along with the SacII-NotI fragments from $\mathrm{pBS} \Delta-\mathrm{E},-\mathrm{F}$, or -G into pVLGS cut with BamHI and NotI.

Recombinant baculovirus was generated by transfection of Sf9 cells with pVLGS derivatives along with wild-type Autographa californica nuclear polyhedrosis virus DNA, using standard protocols. In each case, several independent clones were plaque purified and characterized. For protein production, Sf21 cells (Invitrogen) were infected with high-titer virus in 1-liter roller bottles (approximately $20 \mathrm{ml}$ of virus per $10^{8}$ cells). After $90 \mathrm{~min}, 180 \mathrm{ml}$ of Grace's medium (supplemented with $10 \%$ fetal bovine serum, $2 \%$ [vol/vol] yeastolate, and lactalbumin hydrolysate [GIBCO] plus antibiotics) was added, and bottles were incubated at $26^{\circ} \mathrm{C}$ for a further 2 days. Cells were harvested, washed in cold phosphate-buffered saline, and lysed in TXB with $1 \mathrm{mM}$ dithiothreitol on ice for $30 \mathrm{~min}$, and lysates were cleared by centrifugation at $12,000 \times g$ for $15 \mathrm{~min}$. GST fusion proteins were purified by incubating lysates with glutathione-agarose beads (Molecular Probes, Inc.) at $4^{\circ} \mathrm{C}$ for $90 \mathrm{~min}$, washing extensively in TNGT buffer $(10 \mathrm{mM}$ Tris [ $\mathrm{pH}$ 8.0 ], $150 \mathrm{mM} \mathrm{NaCl}, 10 \%$ glycerol, $1 \%$ Triton $\mathrm{X}-100,1 \mathrm{mM}$ dithiothreitol), and eluting with TNGT plus $20 \mathrm{mM}$ reduced glutathione and $100 \mathrm{mM}$ Tris (pH 8.8). For thrombin cleavage, washed glutathione-agarose beads bound to GST-Abl fusion proteins were incubated with an empirically determined amount of human thrombin (Calbiochem) in TNGT supplemented with $2.5 \mathrm{mM} \mathrm{CaCl}_{2}$, and the eluted cleaved $\mathrm{Abl}$ proteins were separated from beads by pouring into a disposable column. $\mathrm{Na}_{2}$ EDTA was added to $2.5 \mathrm{mM}$, and phenylmethylsulfonyl fluoride was added to $1 \mathrm{mM}$ to inactivate thrombin. Purified proteins were stored at $-70^{\circ} \mathrm{C}$.

For in vitro kinase assays, purified proteins were incubated in $50 \mathrm{mM} N$-2-hydroxyethy piperazine- $N^{\prime}$-2-ethanesulfonic acid (HEPES; pH 7.5)-5 mM MgCl $-0.5 \mathrm{mg}$ of poly(Glu-Tyr) (4:1; Sigma P-0275) per ml-50 $\mu \mathrm{g}$ of acetylated bovine serum albumin (BSA) per ml-1 mM cold ATP-10 $\mu \mathrm{Ci}$ of $\left[\gamma^{-32} \mathrm{P}\right] \mathrm{ATP}$ in $20 \mu \mathrm{l}$ (total volume) at $4^{\circ} \mathrm{C}$ for $20 \mathrm{~min}$. Reactions were stopped with $5 \mu$ l of $5 \times$ Laemmli sample buffer, boiled, and run on SDS-polyacrylamide gels. Gels were stained with Coomassie blue, fixed in $10 \%$ acetic acid-20\% methanol, dried, and exposed for autoradiography. Quantitative assays using angiotensin as a substrate were performed essentially as described previously (9). Reaction mixtures contained $50 \mathrm{mM}$ HEPES (pH 7.5), $10 \mathrm{mM} \mathrm{MgCl}{ }_{2}, 100 \mu \mathrm{M}\left[\gamma^{-32} \mathrm{P}\right] \mathrm{ATP}(\sim 1,000$ $\mathrm{cpm} / \mathrm{pmol}$ ), and $1 \mathrm{mg}$ of [ $\left.\mathrm{Val}^{5}\right]$ angiotensin II (Sigma A-2900) per ml. Reactions were performed at $30^{\circ} \mathrm{C}$, and $25-\mu l$ aliquots were stopped at various time points with $35 \mu$ of $10 \%$ trichloroacetic acid and incubated on ice. Aliquots were briefly centrifuged, and $30 \mu \mathrm{l}$ of the supernatant was spotted on a $4-\mathrm{cm}^{2}$ piece of phosphocellulose paper (Whatman P81). Filters

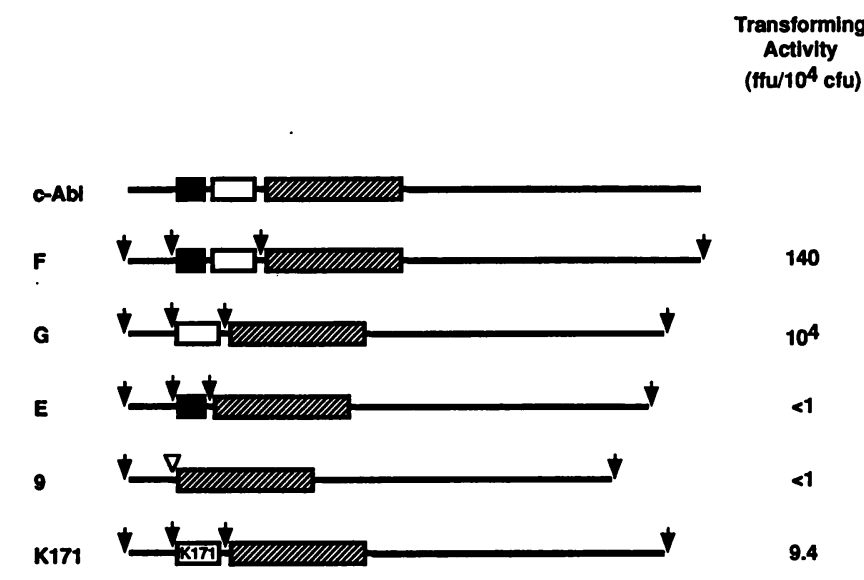

FIG. 1. Effects of $\mathrm{SH} 3$ and $\mathrm{SH} 2$ domains on transforming activities of c-Abl-derived mutants. Mutants are depicted diagrammatically. Black boxes, SH3 domain; white boxes, $\mathrm{SH} 2$ domain; hatched boxes, catalytic domain. Arrowheads indicated the position of unique restriction sites inserted by PCR. The white triangle indicates the position of short synthetic adaptor sequence. K171 denotes a mutant SH2 domain with an arginine-to-lysine mutation at position 171 that drastically reduces binding to phosphotyrosine. Transforming activity value given is the normalized average of morphologically transformed foci per $10^{4}$ G418-resistant colonies for each mutant (see Table 1 and text for details). ffu, focus-forming units.

were washed three times with ice-cold $0.5 \%$ phosphoric acid, washed once with acetone, and dried, and Cerenkov counts were determined. Data points shown are the mean of triplicate samples.

\section{RESULTS}

To analyze the roles of the $\mathrm{SH} 2$ and $\mathrm{SH} 3$ domains in $\mathrm{Abl}$, we constructed a modularized $\mathrm{Abl}$ gene by inserting unique restriction sites flanking the $\mathrm{SH} 3$ and $\mathrm{SH} 2$ domains, using PCR (Fig. 1). This cassette system allowed individual $\mathrm{SH} 2$ or $\mathrm{SH} 3$ domains or the block of $\mathrm{SH} 3$ plus $\mathrm{SH} 2$ domains to be easily manipulated. For some constructs, another unique site was inserted $\mathrm{C}$ terminal to the catalytic domain, allowing insertion of sequences or swapping of catalytic domains. The location of all linkers was chosen to be in predicted loop regions between modular units of protein structure so that disruption of secondary and tertiary structure of the resulting proteins would be minimized. Furthermore, the spacing between elements of structure was conserved in the mutants. All of the constructs in this study encode the myristoylated type IV N terminus of Abl, because previous studies have shown that it is difficult to overexpress proteins encoding the nonmyristoylated type I $\mathrm{N}$ terminus $(10,15 a)$.

All mutant $\mathrm{Abl}$ genes were inserted into a simple retroviral vector derived from pGD (7). This vector contains all sequences required in cis for expression and packaging of the genome and also encodes the neomycin resistance gene, allowing selection of infected cells with G418. When cotransfected with pZAP, which encodes a replication-competent Moloney murine leukemia virus helper, infectious particles encoding the mutant Abl genes are produced.

A transient transfection system was used to produce virus for these studies (36). 293 cells, a human kidney-derived cell line, were transfected with helper and pGD-derived plasmids, and virus was harvested 2 days posttransfection. This protocol minimizes mutation due to error-prone reverse transcription, 
TABLE 1. Quantification of transformed foci and G418-resistant colonies

\begin{tabular}{|c|c|c|c|c|c|c|}
\hline \multirow{2}{*}{ Mutant } & \multicolumn{2}{|c|}{ Raw data ${ }^{a}$} & \multirow{2}{*}{$\begin{array}{l}\text { Foci } / 10^{4} \\
\text { CFU }^{b}\end{array}$} & \multirow{2}{*}{ Normalized $^{c}$} & \multirow{2}{*}{$\mathrm{Avg}^{d}$} & \multirow{2}{*}{$n^{e}$} \\
\hline & Foci/ml & $\mathrm{CFU} / \mathrm{ml}$ & & & & \\
\hline GDN & $<10$ & $7.2 \times 10^{5}$ & $<1$ & $<1$ & $<1$ & 10 \\
\hline $\mathrm{E}$ & $<10$ & $6.8 \times 10^{5}$ & $<1$ & $<1$ & $<1$ & 2 \\
\hline $\mathrm{F}$ & 580 & $4.0 \times 10^{4}$ & 145 & 85 & 140 & 3 \\
\hline G & $8.9 \times 10^{4}$ & $5.2 \times 10^{4}$ & $1.7 \times 10^{4}$ & $10^{4}$ & $10^{4}$ & 10 \\
\hline 9 & $<10$ & $7.4 \times 10^{5}$ & $<1$ & $<1$ & $<1$ & 2 \\
\hline $\mathrm{DE}$ & $\mathrm{ND}^{f}$ & ND & & & $<4$ & 2 \\
\hline DF & ND & ND & & & $<10$ & 2 \\
\hline DG & 15 & $6.5 \times 10^{4}$ & $<3$ & $<2$ & $<2.5$ & 2 \\
\hline D9 & ND & ND & & & $<2$ & 2 \\
\hline K171 & 320 & $2.0 \times 10^{5}$ & 16 & 9.4 & 9.4 & 2 \\
\hline 23 & $2.7 \times 10^{4}$ & $3.6 \times 10^{4}$ & $7.5 \times 10^{3}$ & $4.4 \times 10^{3}$ & $5.2 \times 10^{3}$ & 2 \\
\hline 323 & $1.1 \times 10^{4}$ & $2.3 \times 10^{4}$ & $4.8 \times 10^{3}$ & $2.8 \times 10^{3}$ & $2.5 \times 10^{3}$ & 3 \\
\hline FN & $3.5 \times 10^{4}$ & $2.2 \times 10^{4}$ & $1.6 \times 10^{4}$ & $9.4 \times 10^{3}$ & $6.1 \times 10^{3}$ & 5 \\
\hline GG & $1.5 \times 10^{3}$ & $7.2 \times 10^{4}$ & 210 & 120 & 120 & 4 \\
\hline GS & $5.2 \times 10^{3}$ & $8.5 \times 10^{4}$ & 620 & 360 & 510 & 3 \\
\hline GP & $6.2 \times 10^{4}$ & $5.0 \times 10^{4}$ & $1.2 \times 10^{4}$ & $7.1 \times 10^{3}$ & $3.3 \times 10^{3}$ & 3 \\
\hline GC & $1.4 \times 10^{5}$ & $1.4 \times 10^{4}$ & $10^{5}$ & $5.9 \times 10^{4}$ & $2.2 \times 10^{4}$ & 4 \\
\hline GSC & $2.4 \times 10^{3}$ & $4.6 \times 10^{4}$ & 520 & 310 & 460 & 3 \\
\hline GSC-G & $2.6 \times 10^{3}$ & $4.7 \times 10^{4}$ & 550 & 320 & 340 & 2 \\
\hline GSC-S & $1.1 \times 10^{4}$ & $5.5 \times 10^{4}$ & $2.0 \times 10^{3}$ & $1.2 \times 10^{3}$ & $1.2 \times 10^{3}$ & 2 \\
\hline GSC-P & $2.7 \times 10^{4}$ & $2.8 \times 10^{4}$ & $9.6 \times 10^{3}$ & $5.6 \times 10^{3}$ & $4.9 \times 10^{3}$ & 2 \\
\hline GSC-C & $9.2 \times 10^{3}$ & $1.3 \times 10^{3}$ & $7.1 \times 10^{4}$ & $4.2 \times 10^{4}$ & $1.9 \times 10^{4}$ & 3 \\
\hline GAG & ND & ND & & & $9.4 \times 10^{3}$ & 2 \\
\hline GGA & ND & ND & & & $1.2 \times 10^{4}$ & 2 \\
\hline $2 \mathrm{~N} 3 \mathrm{~K} 2$ & $2.0 \times 10^{4}$ & $2.0 \times 10^{4}$ & $10^{4}$ & $5.9 \times 10^{3}$ & $5.8 \times 10^{3}$ & 2 \\
\hline K2N32 & $1.9 \times 10^{4}$ & $2.8 \times 10^{4}$ & $6.8 \times 10^{3}$ & $4.0 \times 10^{3}$ & $4.2 \times 10^{3}$ & 2 \\
\hline
\end{tabular}

${ }^{a}$ Data from a single transfection and subsequent assay of morphologically transformed focus titer and G418 resistance colony titer.

${ }^{b}$ Transformed focus titer normalized to $\mathrm{G} 418$ resistance colony titer.

${ }^{c}$ Values from previous column normalized to give the mutant $\mathrm{G}$ a value of $10^{4}$ foci $/ 10^{4} \mathrm{CFU}$ (i.e., in this case dividing all values by 1.7 ).

${ }^{d}$ Mean normalized titer (averaged over the number of independent experiments given in the next column).

${ }^{e}$ Number of independent transfections used to generate average normalized titer (previous column).

${ }^{f} \mathrm{ND}$, not done in this experiment.

because at most two rounds of replication are undergone before the mutant genome is scored for biological activity. Transforming activity was assessed by infection of NIH 3T3 cells with dilutions of the 293 cell-derived virus and scoring parallel sets of dishes for morphologically transformed foci and G418-resistant colonies.

The raw numbers of transformed foci and G418-resistant colonies varied considerably from experiment to experiment, so data were normalized in two ways (Table 1). First, all transformation scores were normalized to virus titer by dividing transformed foci by G418-resistant colonies and expressed as transformed foci per $10^{4}$ G418-resistant colonies. A second normalization was required so that data from separate transfections could be combined and averaged. This involved multiplying all scores within a given experiment by a normalization constant such that a fully transforming benchmark mutant (GDN-G) had a score of $10^{4}$ foci per $10^{4}$ G418-resistant colonies (in practice, the normalization constant had values of between 0.5 and 2). All transformation data reported in this paper were derived from at least two independent transfections. Raw data from one representative experiment is shown in Table 1 for reference.

For all mutants, transfected 293 cells used for production of virus were also analyzed by Western blotting (immunoblotting) with Abl-specific antisera. This analysis confirmed that the mutant proteins were of the expected molecular weight and were produced in reasonable quantities (data not shown). In vitro kinase assays were also performed on immunoprecipitates from the 293 cell lysates to ensure that the mutant proteins were active as protein-tyrosine kinases (data not shown).

Effect of SH2 and SH3 domain deletion. The first series of mutants was constructed to test whether our mutagenic approach was viable and to confirm the presumed inhibitory role of the $\mathrm{SH} 3$ domain and positive role of the $\mathrm{SH} 2$ domain in transformation by Abl (Fig. 1). When the linker-modified c-Abl construct (termed GDN-F) was assayed for transforming activity, only very low activity was observed (less than 150 foci per $10^{4}$ G418-resistant colonies). We believe that this weak transforming activity was detected in our experiments, unlike earlier studies $(10,15,32)$, because our expression strategy did not involve long-term selection of cells expressing c-Abl, which is strongly cytostatic $(15,15 \mathrm{a}, 42)$ and we assayed morphological alteration and not soft-agar colony growth. It is also possible that the insertion of two restriction sites by PCR had a slight activating effect. This c-Abl background was very small, however, relative to the transforming activity of a mutant in which the SH3 domain was deleted (GDN-G), which was approximately 100 -fold higher. In a number of separate experiments, focus-forming titers with this virus were approximately equal to G418 resistance titers suggesting that virtually every infected cell produced a morphologically transformed focus. These foci were in general larger than the few foci seen with the undeleted c-Abl-expressing construct.

When the $\mathrm{SH} 2$ domain was deleted, either in the presence or in the absence of the SH3 domain (GDN-E and -9, respectively), transforming activity was undetectable (Fig. 1). Furthermore, when the $\mathrm{SH} 2$ domain of a mutant lacking the $\mathrm{SH} 3$ 


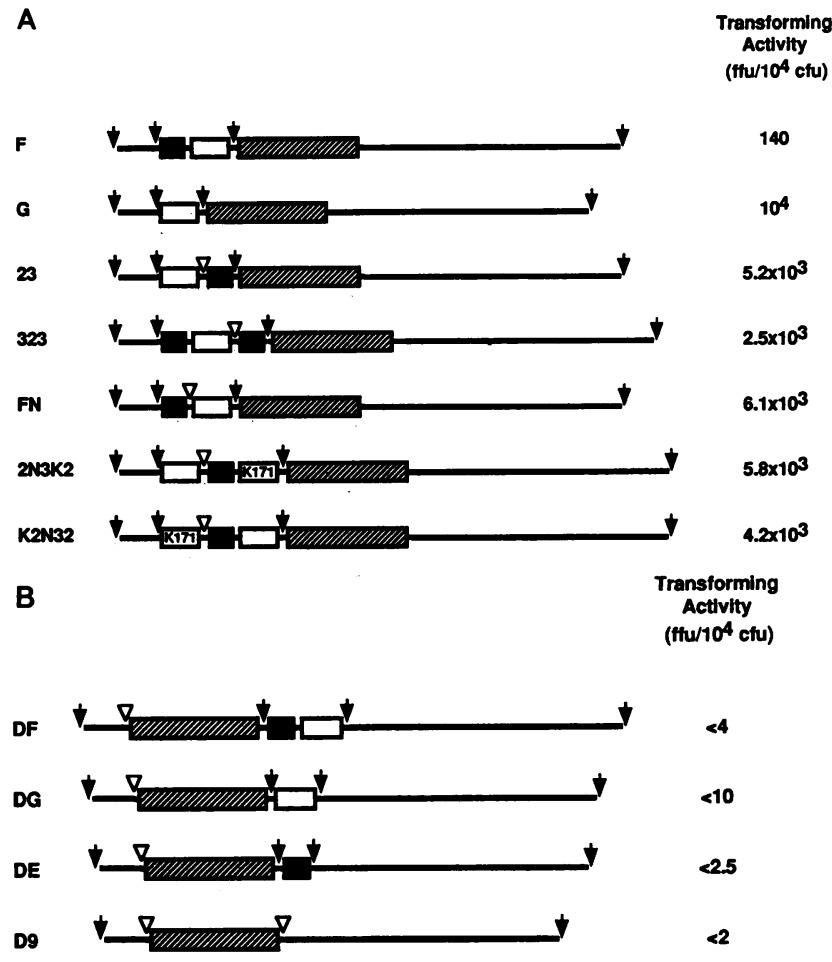

FIG. 2. Effects of altering positions of $\mathrm{SH} 3$ and $\mathrm{SH} 2$ domains on transforming activities of $\mathrm{Abl}$ mutants. Structures and transforming activities are depicted as in Fig. 1. (A) Mutants with SH2 domains $\mathrm{N}$ terminal to the catalytic domain. (B) Mutants with SH2 and SH3 domains deleted from their normal $\mathrm{N}$-terminal positions and introduced $\mathrm{C}$ terminal to the catalytic domain. ffu, focus-forming units.

contained an arginine-to-lysine mutation at position 171 (R171K), which has been shown to be essential for binding to phosphotyrosine (26), transforming activity was drastically reduced relative to the same construct with an unmutated $\mathrm{SH} 2$ domain. These results are consistent with previously published results showing that deletion of the $\mathrm{SH} 3$ domain leads to activation of c-Abl and that a functional $\mathrm{SH} 2$ domain is required for transforming activity. Therefore, the insertion of linkers by PCR did not significantly alter the biological activity of $\mathrm{Abl}$ or mutants derived from it.

Position dependence of $\mathrm{SH} 2$ and $\mathrm{SH} 3$ domain function. The next series of mutants was constructed to test whether the negative function of the $\mathrm{SH} 3$ domain and the positive function of the $\mathrm{SH} 2$ domain were dependent on their positions within the Abl protein. Mutants were constructed in which the positions of the $\mathrm{SH} 2$ and $\mathrm{SH} 3$ domains were changed relative to each other and to the $\mathrm{N}$ terminus or catalytic domain. These mutants contained at least one functional $\mathrm{SH} 2$ and $\mathrm{SH} 3$ domain, and some contained an additional $\mathrm{SH} 2$ domain with the $\mathrm{R} 171 \mathrm{~K}$ mutation to render it nonfunctional. All of these mutants had transforming activities nearly as great as that of the SH3 domain-deleted positive control (Fig. 2A), demonstrating that the context of the $\mathrm{SH} 3$ domain is extremely important to its ability to inhibit transforming activity of Abl.

It is clear from these mutants that the relationship with more than one part of the protein is important, since in at least one of the mutants, the position of the $\mathrm{SH} 3$ domain is unchanged relative to either the $\mathrm{N}$ terminus, $\mathrm{SH} 2$ or catalytic domain, and $\mathrm{C}$ terminus. In mutant 23 , the positions of the $\mathrm{SH} 2$ and $\mathrm{SH} 3$ domains are swapped, and the SH3 domain is in an altered position relative to the $\mathrm{N}$ terminus, $\mathrm{SH} 2$ domain, and catalytic domain. In mutant 323, a second SH3 domain is inserted between the $\mathrm{SH} 2$ and catalytic domains; the position of the $\mathrm{N}$-terminal SH3 domain is altered only relative to the catalytic domain. In mutant $\mathrm{FN}$, three amino acids were inserted between the $\mathrm{SH} 3$ and $\mathrm{SH} 2$ domains, subtly altering the position of the $\mathrm{SH} 3$ domain relative to the catalytic and $\mathrm{SH} 2$ domains. In mutant $2 \mathrm{~N} 3 \mathrm{~K} 2$, the $\mathrm{SH} 3$ domain is in an altered position relative to the $\mathrm{N}$ terminus and the functional $\mathrm{SH} 2$ domain, and in mutant $\mathrm{K} 2 \mathrm{~N} 32$, a nonfunctional SH2 domain is inserted upstream of the $\mathrm{SH} 3$ domain, altering its position only relative to the $\mathrm{N}$ terminus.

Another implication of the results shown in Fig. 2A is that unlike the $\mathrm{SH} 3$ domain, the $\mathrm{SH} 2$ domain can function in different positions within the Abl protein. In mutant GDN$2 \mathrm{~N} 3 \mathrm{~K} 2$, the functional $\mathrm{SH} 2$ domain is approximately 150 aa $\mathrm{N}$ terminal to its normal position relative to the catalytic domain, yet transforming activity is essentially equivalent to that of the positive SH3 domain-deleted control. To test whether the $\mathrm{SH} 2$ or SH3 domain could function in a radically different context, a series of mutants was constructed with the $\mathrm{SH} 3$ and $\mathrm{SH} 2$ domains deleted from their normal positions $\mathrm{N}$ terminal to the catalytic domain and inserted alone or in combination in a novel position $\mathrm{C}$ terminal to the catalytic domain (Fig. 2B). None of these constructs had significant transforming activity, although they produced proteins that were kinase active and present in amounts comparable to those shown in Fig. 2A (data not shown). This finding demonstrates that while there can be considerable flexibility in the position of the $\mathrm{SH} 2$ domain, it is not entirely position independent since it cannot effectively perform its positive role when $\mathrm{C}$ terminal to the catalytic domain.

Complementation of loss of the SH2 domain by heterologous SH2 domains. $\mathrm{SH} 2$ domains all have the ability to bind to tyrosine-phosphorylated proteins, but different $\mathrm{SH} 2$ domains bind to different specific binding sites (50). We were therefore interested in whether $\mathrm{Abl}$ transformation was dependent on the presence of the $\mathrm{Abl} \mathrm{SH} 2$ domain, or whether $\mathrm{SH} 2$ domains from other proteins, with different binding specificities, would restore transforming ability in Abl mutants lacking the Abl $\mathrm{SH} 2$ domain. We constructed a series of mutants in which the $\mathrm{SH} 3$ domain was deleted to activate the transforming activity of c-Abl, and the $\mathrm{Abl} \mathrm{SH} 2$ domain was replaced by the $\mathrm{SH} 2$ domain of Src or Crk, the N-terminal SH2 domain of GAP, or the C-terminal SH2 domain of the p85 PI 3-kinase subunit (Fig. 3A). When assayed, all of the mutants with heterologous SH2 domains had detectable transforming activity, whereas transformation was undetectable in the absence of any $\mathrm{SH} 2$ domain. Activities ranged from 100-fold less active (for the GAP SH2 domain) to at least as active (for the Crk SH2 domain) as the $\mathrm{Abl} \mathrm{SH} 2$ domain-containing positive control (Fig. 3A). This finding demonstrates that transforming activity is not strictly dependent on the $\mathrm{Abl} \mathrm{SH} 2$ domain, and that $\mathrm{SH} 2$ domains with very different binding specificities could function to promote transforming activity. The very low activity of the construct with the mutant $\mathrm{Abl} \mathrm{SH} 2$ domain that is unable to bind to phosphotyrosine (GDN-K171 in Fig. 1) demonstrates that this requirement is not merely structural but requires the ability to bind to phosphotyrosine.

When viruses encoding the $\mathrm{SH} 2$ domain swap mutants described above were used to infect $3 \mathrm{~T} 3$ cells and tyrosinephosphorylated proteins were analyzed by immunoblotting, the pattern of tyrosine phosphorylation differed in the mutants (Fig. 4A). The pattern of phosphoproteins seemed to correlate with the proteins for which the specific $\mathrm{SH} 2$ domain had high affinity. For example, we have previously shown that the 


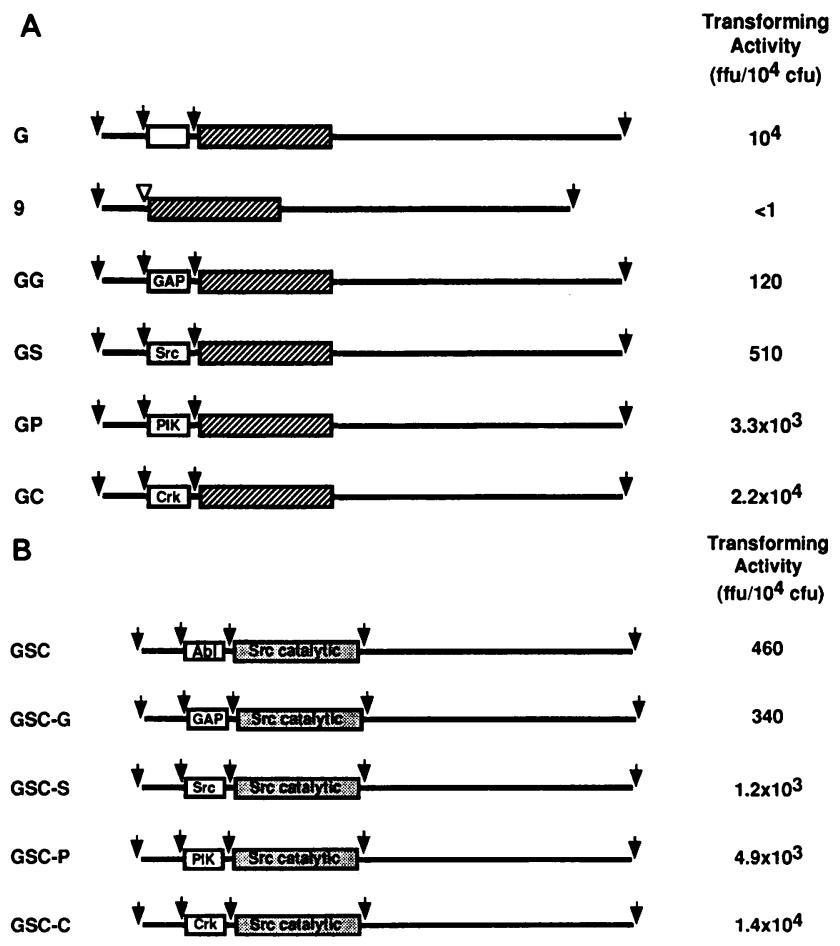

FIG. 3. Effects of heterologous $\mathrm{SH} 2$ and catalytic domains on transforming activities of Abl mutants. Structures and transforming activities are depicted as in Fig. 1. The origin of the $\mathrm{SH} 2$ domain is indicated within the white boxes. GAP, N-terminal SH2 domain of Ras-GAP; PIK, C-terminal SH2 of p85 subunit of PI 3-kinase. (A) Mutants with the Abl catalytic domain. (B) Mutants in which the Abl catalytic domain is replaced with that of Src. ffu, focus-forming units.

$\mathrm{N}$-terminal GAP SH2 domain has a very high affinity for a protein of approximately $68 \mathrm{kDa}(26)$, and a tyrosine-phosphorylated protein of this molecular mass is most prominent in cells infected by the GAP SH2 domain-containing mutant. Similarly, the Crk SH2 domain has high affinity for proteins in the 135 - to $155-\mathrm{kDa}$ range $(3,22,24 \mathrm{a})$, and tyrosine-phosphor- ylated proteins of this molecular mass are prominent in cells infected with the Crk SH2 domain-containing mutant. Surprisingly, there was no apparent correlation between overall phosphotyrosine levels and transforming efficiency.

We next examined whether any of the tyrosine-phosphorylated proteins were physically associated with the Abl proteins. We immunoprecipitated $\mathrm{Abl}$ from infected cell lysates, separated the immunoprecipitated proteins on gels, and immunoblotted them with a phosphotyrosine-specific antibody (Fig. 4C). In each lane, several tyrosine-phosphorylated proteins in addition to $\mathrm{Abl}$ itself were observed, suggesting that they were physically associated with the Abl product. Furthermore, the pattern of coprecipitating proteins varied with the $\mathrm{SH} 2$ domain, accentuating the differences seen in whole lysates and suggesting that these tyrosine-phosphorylated proteins might be bound to $\mathrm{Abl}$ by $\mathrm{SH} 2$-phosphotyrosine interactions and that this might be the cause of the difference in the overall pattern of tyrosine phosphorylation.

Effect of replacing the Abl catalytic domain. Since the experiments described above suggested that the pattern of phosphoproteins observed when activated Abl is overexpressed depends on the $\mathrm{SH} 2$ domain, we examined the role of the catalytic domain in determining this pattern. We generated a series of mutants with various $\mathrm{SH} 2$ domains, similar to those shown in Fig. 3A but with the Abl catalytic domain replaced with that of p60 $0^{\mathrm{c}-s r c}$. As shown in Fig. 3B, all of these mutants had detectable transforming activity. In fact, the hierarchy of transforming activities was very similar to that seen with the Abl catalytic domain: the Crk SH2 domain was the most efficient, followed by that of PI 3-kinase, with the GAP SH2 being the least efficient. The two cases where the correlation broke down were when the $\mathrm{Abl}$ and $\mathrm{Src} \mathrm{SH} 2$ domains were involved; in each case, the catalytic domain was most efficient when paired with its corresponding $\mathrm{SH} 2$ domain. It is remarkable that mutant GSC-C contained pieces of three proteins ( $N$ and $\mathrm{C}$ termini of $\mathrm{Abl}, \mathrm{SH} 2$ domain of $\mathrm{Crk}$, and catalytic domain of Src) and was as transforming as the most highly activated $\mathrm{Abl}$ variants, demonstrating the truly modular nature of these proteins.

The pattern of tyrosine-phosphorylated proteins was also examined in these mutants (Fig. 5A). Again, as in the case with

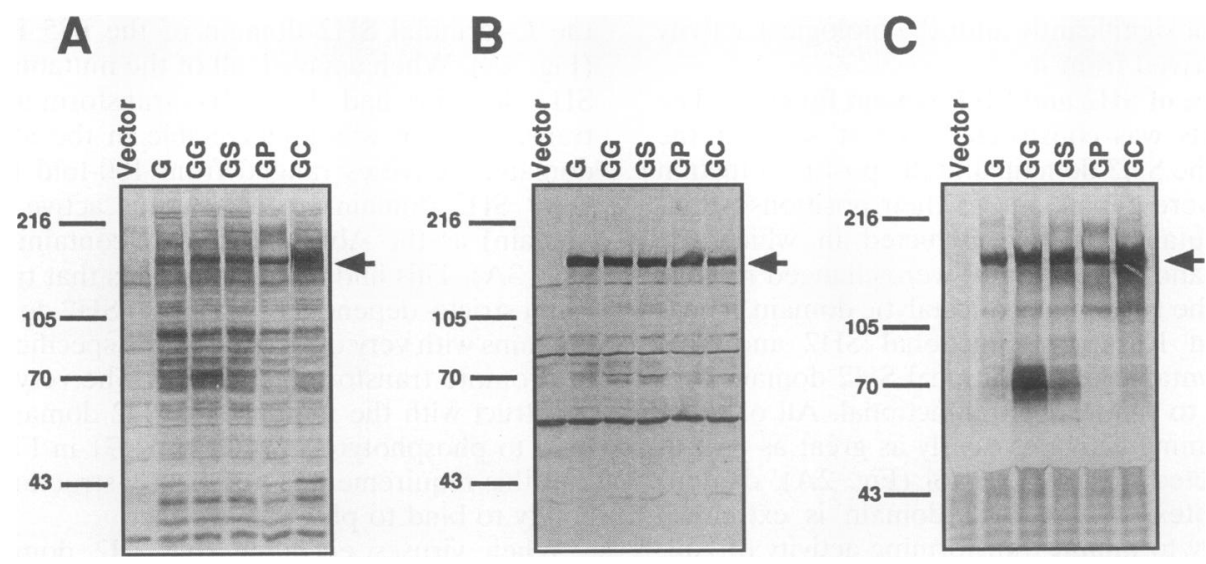

FIG. 4. Characterization of tyrosine-phosphorylated proteins in cells expressing SH2 domain swap mutants. 3T3 cells were infected with high-titer virus stocks expressing mutant Abl genes depicted in Fig. 3A, and lysates were prepared 2 days later. Lanes contain lysates from cells infected with virus as marked. Numbers on the left indicate apparent molecular mass markers in kilodaltons. Arrows indicate approximate positions of mutant Abl proteins. (A) Antiphosphosphotyrosine immunoblot of whole cell lysates. (B) Immunoblot of same lysates with Abl-specific antiserum. (C) Antiphosphotyrosine immunoblot of lysates first immunoprecipitated with Abl-specific serum, showing tyrosine-phosphorylated proteins that coprecipitate with Abl protein. 


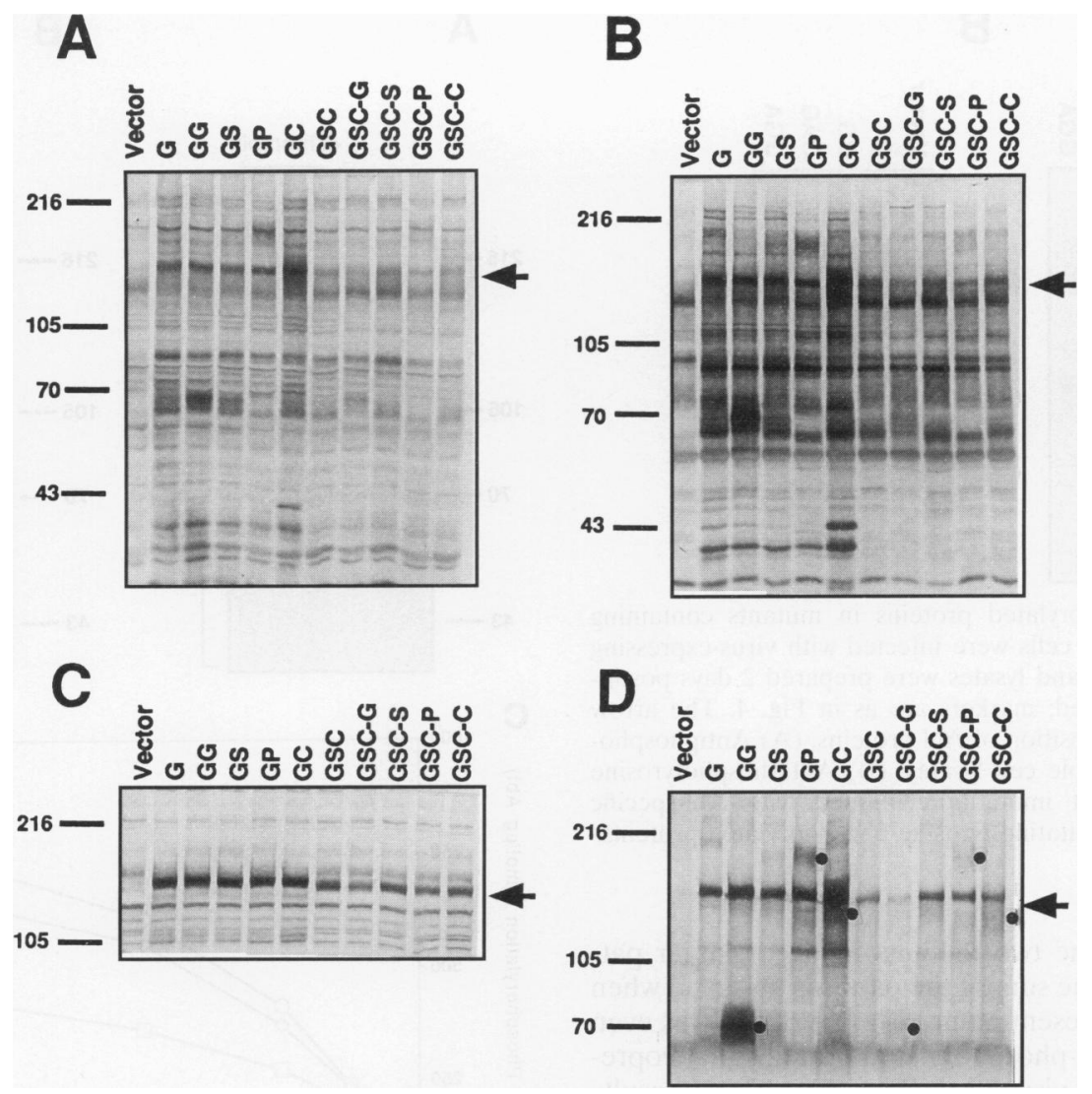

FIG. 5. Tyrosine-phosphorylated proteins in cells expressing mutants with heterologous SH2 and catalytic domains. 3T3 cells were infected with virus-expressing mutants depicted in Fig. 3, and lysates were prepared 2 days after infection. Lanes are as marked; molecular mass markers are as depicted as in Fig. 4. Approximate positions of Abl proteins are indicated by arrows. In panel D, dots indicate the positions of tyrosine-phosphorylated proteins characteristic of mutants containing the GAP, PI 3-kinase, or Crk SH2 domain (approximate molecular masses of 68,180 , and 135 to $155 \mathrm{kDa}$, respectively). (A) Antiphosphotyrosine immunoblot of whole cell lysates. (B) Antiphosphotyrosine immunoblots of lysates first partially purified by binding to beads covalently coupled to antiphosphotyrosine-specific antibody. (C) Immunoblot of whole cell lysates probed with Abl-specific antiserum. (D) Antiphosphotyrosine immunoblot of lysates first immunoprecipitated with Abl-specific antiserum, showing coprecipitating tyrosine-phosphorylated proteins.

the Abl SH2 domain, the pattern of tyrosine-phosphorylated proteins varied with the $\mathrm{SH} 2$ domain. This is more easily seen when the tyrosine-phosphorylated proteins were first immunoprecipitated with antiphosphotyrosine antibody beads (Fig. 5B) or when proteins that coprecipitated with $\mathrm{Abl}$ were analyzed (Fig. 5D) because it has proven difficult to get high-level expression of the mutants with the Src catalytic domain in transient infections (Fig. 5C). These results suggest that the $\mathrm{SH} 2$ domain plays at least as important a role in determining the pattern of tyrosine-phosphorylated proteins seen in cells infected with these Abl mutants as the catalytic domain does.

Role of multiple SH2 domains. We have shown that the transforming potency and ultimate substrate specificity of $\mathrm{Abl}$ mutants is highly dependent on the $\mathrm{SH} 2$ domain. We were further interested in whether the effect of multiple $\mathrm{SH} 2$ domains would be additive, or whether the properties of one $\mathrm{SH} 2$ domain would be dominant in a construct that encoded multiple SH2 domains. For this purpose, we constructed two mutants that contained both the Abl and N-terminal GAP SH2 domains, in the order Abl-GAP or GAP-Abl (Fig. 6). We used these two $\mathrm{SH} 2$ domains because they had the greatest disparity in both transforming activity (100-fold) and the pattern of tyrosine-phosphorylated proteins observed (where the GAP
$\mathrm{SH} 2$ induces the prominent $68-\mathrm{kDa}$ phosphoprotein). Both of these mutants had transforming activities essentially indistinguishable from that of the positive control encoding the Abl $\mathrm{SH} 2$ domain, suggesting that both the proximal and distal $\mathrm{SH} 2$ domains were able to function to promote transformation (Fig. 6 ). Furthermore, when the pattern of tyrosine-phosphorylated

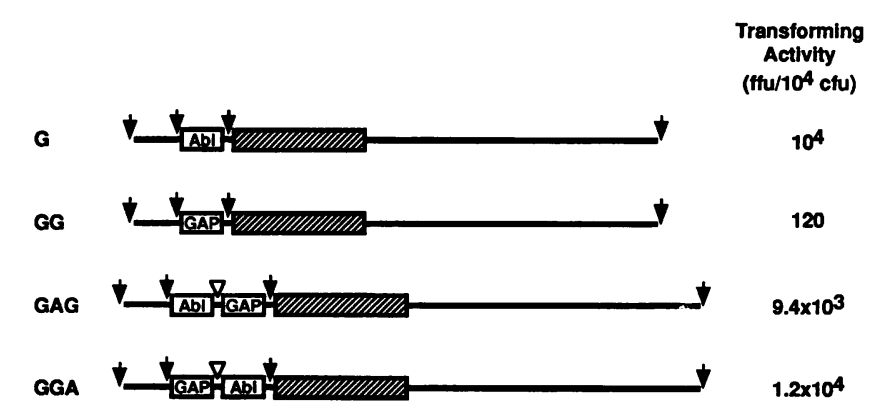

FIG. 6. Mutants containing multiple SH2 domains. Structures and transforming activities of mutants are depicted as in Fig. 1. The origin of each SH2 domain (Abl or N-terminal Ras-GAP SH2 domain) is indicated in a white box. ffu, focus-forming units. 


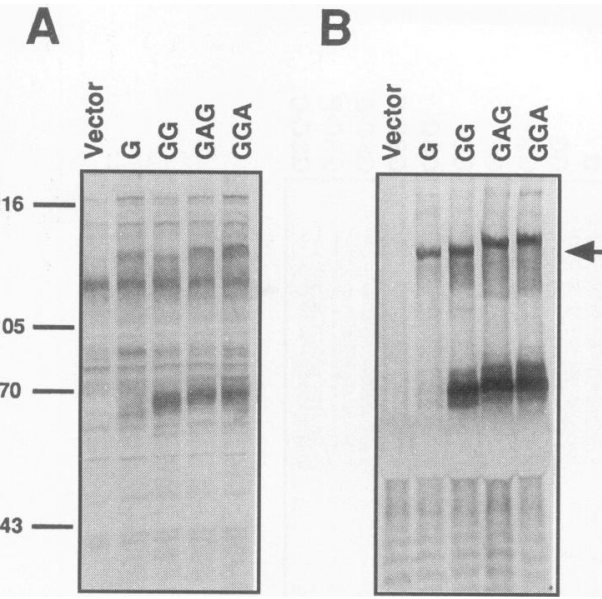

FIG. 7. Tyrosine-phosphorylated proteins in mutants containing multiple SH2 domains. 3T3 cells were infected with virus-expressing mutants depicted in Fig. 6, and lysates were prepared 2 days postinfection. Lanes are as marked; markers are as in Fig. 4. The arrow indicates the approximate position of Abl proteins. (A) Antiphosphotyrosine immunoblot of whole cell lysates. (B) Antiphosphotyrosine immunoblot of lysates first immunoprecipitated with Abl-specific antiserum, showing coprecipitating tyrosine-phosphorylated proteins.

proteins was analyzed, the two mutants induced similar patterns that seemed to be the sum of the patterns observed when each $\mathrm{SH} 2$ domain was present alone (Fig. 7A). This was even clearer when the tyrosine-phosphorylated proteins that coprecipitated with Abl were visualized (Fig. 7B). These results demonstrate that the $\mathrm{SH} 2$ domains function independently and that proximity to the catalytic domain does not appear to affect their activities significantly. The $\mathrm{SH} 2$ domains function additively in that properties of each (efficient transformation by the Abl SH2, phosphorylation of the $68-\mathrm{kDa}$ protein by that of GAP) are conferred on proteins containing both of them.

Effect of SH2 and SH3 domains on purified protein. It is clear from the data presented above that the $\mathrm{SH} 2$ and $\mathrm{SH} 3$ domains have a profound effect on in vivo activity of the $\mathrm{Abl}$ protein. To examine the effect of deletion of these domains on the in vitro activity of purified protein, we have constructed GST fusion proteins encoding the Abl inserts of GDN-F, -G, and -E (intact, $\mathrm{SH} 3$ domain-deleted, and $\mathrm{SH} 2$ domain-deleted c-Abl, respectively; Fig. 1). In each case, GST was fused directly upstream of the position 2 glycine of $\mathrm{Abl}$, so that cleavage with thrombin generated the natural $\mathrm{Abl} N$ terminus except for the lack of the $\mathrm{N}$-terminal myristoyl moiety. The fusion proteins were expressed either in insect cells by using baculovirus vectors or in human 293 cells by using an expression vector driven by the elongation factor $1 \alpha$ promoter (29). In both cases, large quantities of protein were easily purified on glutathione-agarose beads and either eluted with glutathione or cleaved with thrombin.

When the in vitro kinase activities of the three different $\mathrm{Abl}$ proteins were compared, there was no apparent difference (Fig. 8). This was true whether or not the proteins were cleaved from GST (Fig. 8A) or whether proteins were synthesized in insect cells or human cells (not shown). Kinase activity was measured using Abl itself or poly(Glu-Tyr) random copolymer as the substrate and visualized on gels (Fig. 8A) or by using angiotensin II or [ $\left.\mathrm{Val}^{5}\right]$ angiotensin II in a quantitative filter paper assay (Fig. 8C); in all cases, the three proteins had essentially identical kinase activities per microgram of $\mathrm{Abl}$ protein (differences of less than a factor of 2). With use of
A
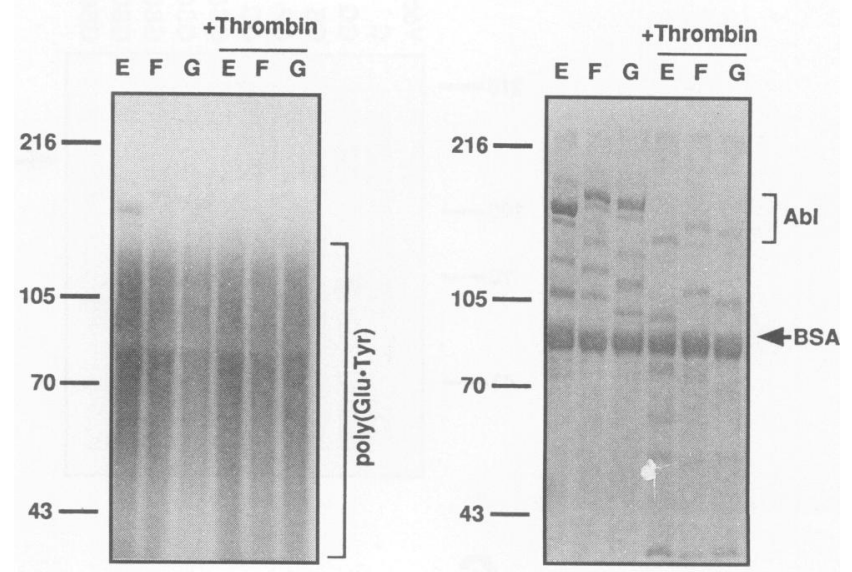

C

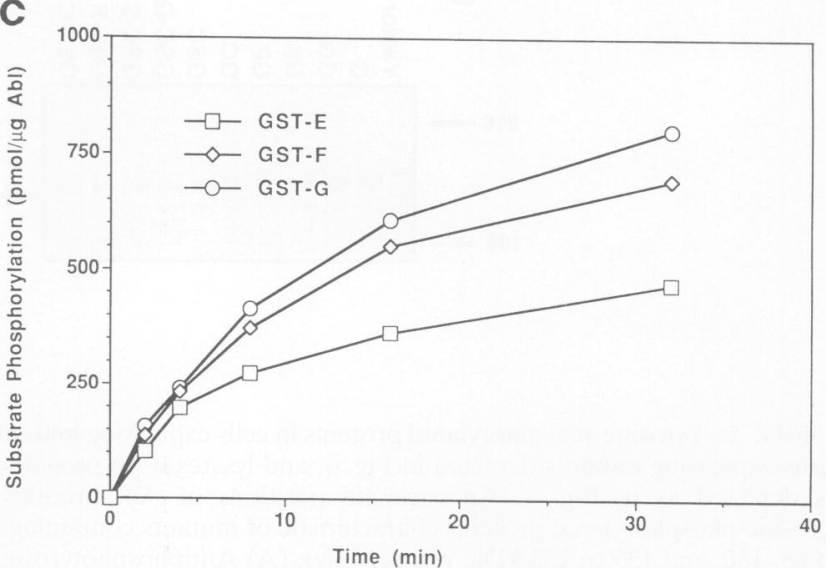

FIG. 8. Effects of $\mathrm{SH} 2$ and $\mathrm{SH} 3$ domains on in vitro kinase activity of purified GST-Abl fusion proteins. GST-Abl fusion proteins encoding the Abl genes of mutants $\mathrm{E}, \mathrm{F}$, and $\mathrm{G}$ (see Fig. 1) were produced in insect cells and purified on glutathione-agarose. Proteins were either eluted or cleaved with thrombin to remove GST, as marked. (A and B) Approximately equal amounts of the six purified protein samples were incubated with $\left[\gamma^{-}{ }^{32} \mathrm{P}\right] \mathrm{ATP}$ and poly(Glu-Tyr) random copolymer to assess kinase activity. Reactions were run on SDS-polyacrylamide gels, stained with Coomassie blue, fixed, dried, and autoradiographed (A) or photographed directly (B). Phosphorylated substrate poly(Glu-Tyr) appears as a smear in panel $\mathrm{A}$. The band at $\sim 85 \mathrm{kDa}$ in panel $\mathrm{B}$ (arrow) is acetylated BSA carrier protein. The approximate position of the full-length Abl proteins is indicated on panel B. Molecular mass markers are as in Fig. 4. (C) Rates of reaction of purified GST fusion proteins were assessed in vitro, using $\left[\mathrm{Val}^{5}\right]$ angiotensin II as the substrate. Results were normalized for protein content.

$\left[\mathrm{Val}^{5}\right]$ angiotensin II at $1 \mathrm{mM}$, initial reaction rates ranged from approximately 7 to 11 pmol of phosphate per min per pmol of $\mathrm{Abl}$ protein (Fig. $8 \mathrm{C}$ and data not shown). These results suggest that the $\mathrm{SH} 3$ and $\mathrm{SH} 2$ domains do not function to regulate the in vivo kinase activity of the Abl kinase in cis but require other cellular factors to exert the differential modulatory activities seen in cells.

\section{DISCUSSION}

In this study, we have constructed a series of mutants of the Abl kinase designed to probe the function of the $\mathrm{SH} 2$ and $\mathrm{SH} 3$ 
domains. We find that the $\mathrm{SH} 3$ domain suppresses the intrinsic transforming activity of the c-Abl protein in cells but that this suppression is extremely position dependent and is not apparent in vitro with use of purified proteins. The $\mathrm{SH} 2$ domain, on the other hand, is absolutely required for transforming activity of $\mathrm{Abl}$ mutants; furthermore, the $\mathrm{SH} 2$ domain appears to indirectly determine the spectrum of proteins phosphorylated in cells. Below, we outline models that are consistent with these data.

These studies start from the observation that the wild-type c-Abl protein is poorly transforming, even at relatively high levels of overexpression, while mutated forms such as v-Abl and Bcr-Abl have a greatly increased ability to induce the uncontrolled growth characteristic of transformation and have elevated in vivo tyrosine kinase activity $(10,15,32)$. This finding suggests that the $\mathrm{c}-\mathrm{Abl}$ product is tightly regulated in cells and that mutated forms can escape this regulation. By analyzing the transforming activity of c-Abl mutants, two issues are simultaneously addressed: first, the nature of the machinery that normally suppresses c-Abl kinase activity, and second, the functions required to allow derepressed $\mathrm{Abl}$ variants to transform. While the first issue is clearly relevant to the normal function of $\mathrm{c}-\mathrm{Abl}$, the second issue may not be. We assume, however, that in some (presently unknown) context, c-Abl kinase activity might be activated, and that this presumably transient activated state is mimicked by constitutively activated transforming variants. Furthermore, understanding the factors required for $\mathrm{Abl}$ transformation has obvious clinical relevance in diseases such as chronic myelogenous leukemia, in which activated $\mathrm{Abl}$ is strongly implicated.

The transformation assay used in this study is morphological alteration of monolayer 3T3 cells. While there are many parameters of cell transformation, we chose morphological change because it is rapidly and easily scored. One caveat of this type of analysis should be mentioned, however. It has been reported that both $\mathrm{c}-\mathrm{Abl}$ and its transforming variants have a toxic or cytostatic effect when overexpressed $(15,42)$. This observation implies that the scores we report for G418 titers and focus titers might not reflect the behavior of the majority of infected cells, since all cells that die or never grow up to a discernible focus or colony are not scored. Indeed, G418 resistance titers for Abl-containing viruses were generally lower than titers for the empty virus (GDN), and SH2 domaincontaining variants tended to give lower titers than those lacking a functional $\mathrm{SH} 2$ domain (see Table 1 for a representative experiment). Given the inherent difficulties in studying toxicity, however, we leave a more careful analysis of the roles of $\mathrm{SH} 2$ and $\mathrm{SH} 3$ domains in this phenomenon for future studies.

Role of the SH3 domain. It has been known for several years that deletion of the c-Abl SH3 domain is sufficient to activate its transforming potential $(10,15)$. Because SH3 domain mutations can also activate c-Src $(17,39)$, it is likely that SH3 domains act to inhibit an intrinsic transforming activity in many tyrosine kinases that contain them. Our data show that the ability of the SH3 domain to repress Abl activity is extremely position sensitive. Moving the SH3 domain relative to other parts of the protein (the $\mathrm{N}$ terminus, $\mathrm{SH} 2$ domain, and catalytic domain) activates the transforming ability of c-Abl at least 20 -fold. Many of the positional changes are quite subtle, yet they result in almost complete derepression of Abl. These results provide important clues to the possible mechanisms whereby the $\mathrm{SH} 3$ domain might repress catalytic activity in vivo. Consistent with our results, another group has found that substituting heterologous $\mathrm{SH} 2$ domains (from GAP or Arg) for that of c-Abl activates c-Abl transforming activity (31), perhaps by subtly altering the relationship of the $\mathrm{SH} 3$ domain to the kinase and $\mathrm{SH} 2$ domains.

The results from the series of mutants shown in Fig. 2A make it likely that the physical relationship between the $\mathrm{SH} 3$ domain and more than one other part of the protein is important for repression. If the $\mathrm{SH} 3$ domain functioned by interacting directly or indirectly with a single part of the protein, one would expect that only mutations affecting the relationship between the $\mathrm{SH} 3$ domain and that part of the protein would activate. This prediction is not borne out by our data. Our results also strongly suggest that the $\mathrm{SH} 3$ domain does not function by a simple trans mechanism, for example by binding to a structural protein and thereby tethering c-Abl in a subcellular compartment incompatible with transformation. If this were the case, it is unlikely that subtle changes in the position of the SH3 domain would affect its activity.

Another possible mechanism for SH3 domain function would be for it to act in cis to inhibit kinase activity, for example by binding to some other part of the protein to hold the protein in a catalytically inactive conformation (reviewed in reference 56). The SH3 domain of c-Src is proposed to collaborate with the $\mathrm{SH} 2$ domain to inhibit activity by such a mechanism (51). The Abl SH3 domain is known to bind to proline-rich sequences, and a 9- or 10-aa high-affinity binding site has been identified $(4,41)$. While the C-terminal half of $\mathrm{c}-\mathrm{Abl}$ is relatively proline rich, it does not bind with high affinity to the Abl SH3 domain (40a). Furthermore, if the SH3 domain functioned in cis by binding to $\mathrm{Abl}$ itself, the in vitro kinase activity of c-Abl protein would be expected to be lower than that of variants lacking the SH3 domain. This is not the case: using several substrates, we found no difference in the kinase activity of purified Abl proteins, whether or not the SH3 domain was present.

How, therefore, does the $\mathrm{SH} 3$ domain repress the in vivo activity of c-Abl? Any viable model must explain the position dependence of the $\mathrm{SH} 3$ domain and its inability to inhibit the activity of purified proteins. The most likely possibility is that the SH3 domain binds to a cellular factor that inhibits catalytic activity. The existence of such a factor has been previously suggested (37). SH3 domains are known to function as protein association domains during signaling (27), and several highaffinity $\mathrm{Abl} \mathrm{SH} 3$ domain ligands have been isolated $(4,41)$. The observation that in vitro kinase activities are not $\mathrm{SH} 3$ domain dependent suggests that such an inhibitor does not bind tightly enough to copurify; consistent with this, we have found that it is difficult to coimmunoprecipitate $\mathrm{Abl}$ and known $\mathrm{Abl} \mathrm{SH3}$ domain-binding proteins under standard conditions (1). The extreme position sensitivity of the effect of the $\mathrm{SH} 3$ domain could be explained if the putative inhibitor had to make specific three-dimensional contacts with multiple surfaces of the protein in order to inhibit the kinase. For example, it might be necessary for the inhibitor to precisely interact with the catalytic active site, and moving the SH3 would make this interaction sterically unfavorable or even make the $\mathrm{SH} 3$ domain inaccessible for binding. Previous work has revealed an Abl catalytic site mutation that can activate transforming potential in the presence of a normal SH3 domain, consistent with such a model (16).

While the model outlined above is clearly speculative, it is consistent with the known behavior of $\mathrm{c}-\mathrm{Abl}$ and its variants. It also suggests how the system might be regulated-by modification either of the inhibitor or of Abl itself-allowing for an activated state for $\mathrm{c}$-Abl under some physiological conditions. It is possible that in such an activated state, the $\mathrm{Abl} \mathrm{SH} 3$ domain might bind other proteins, such as 3BP-1 (4), which contains a domain with GAP activity for the Rho/Rac family of 
Ras-like GTP-binding proteins, serving to tie c-Abl into other signaling pathways. Of course, such potential interactions must not be required for cell transformation, since $\mathrm{SH} 3$ domaindeleted mutants are fully activated for cell transformation.

Role of the SH2 domain in transformation. Unlike the $\mathrm{SH} 3$ domain, the $\mathrm{SH} 2$ domain of the $\mathrm{Abl}$ kinase plays a positive role in transformation. If the $\mathrm{SH} 2$ domain is deleted, or if it is mutated at a residue that is critical for binding to phosphotyrosine, transforming activity is almost completely lost, even in the absence of the $\mathrm{SH} 3$ domain. Abl proteins that lack a functional $\mathrm{SH} 2$ domain retain wild-type levels of in vitro kinase activity, assayed with purified proteins made either in insect cells (Fig. 8) or in immunoprecipitates from infected 293 or $3 \mathrm{~T} 3$ cells (not shown), suggesting that the $\mathrm{SH} 2$ domain does not function by modulating the kinase domain directly.

These results raise the question of why a tyrosine kinase would require an $\mathrm{SH} 2$ domain, whose function is to tightly bind to tyrosine-phosphorylated proteins, in order to transform. Several possibilities will be considered. First, since the nontransforming c-Abl protein is localized largely in the nucleus (54), it is possible that the $\mathrm{SH} 2$ domain functions (when the kinase domain is activated, for example by $\mathrm{SH} 3$ deletion) to tether Abl via SH2-phosphotyrosine interactions in the cytoplasm, where it must be in order to transform. However, SH3 domain-deleted $\mathrm{Abl}$ mutants bearing the R171K mutation that abolishes $\mathrm{SH} 2$ domain function are localized in the cytoplasm (53a), suggesting that a functional $\mathrm{SH} 2$ domain is not necessary for cytoplasmic localization.

A second possibility is that the $\mathrm{SH} 2$ domain functions to tether substrate proteins to the plasma membrane. In signal transduction by receptor tyrosine kinases, a critical step of signaling is the binding of normally cytoplasmic signaling proteins, such as phospholipase C- $\gamma$, GAP, PI 3-kinase, and GRB-2, to the membrane by interaction of their $\mathrm{SH} 2$ domains with phosphotyrosine residues on the activated receptor (reviewed in references 33,35 , and 46). Since transforming Abl variants are myristoylated and at least partially localized on the plasma membrane $(15,54)$, the same effect would be achieved if the Abl kinase phosphorylated such proteins on tyrosine and then tightly bound them via its $\mathrm{SH} 2$ domain. We have tested this hypothesis by expressing two Abl variants in one cell, the first containing the $\mathrm{R} 171 \mathrm{~K}$ mutant $\mathrm{SH} 2$ domain and lacking the SH3 domain, and the second containing a functional SH2 domain but bearing an ATP binding site mutation (K290M) that inactivates catalytic activity $(15 \mathrm{a})$. Each of these mutants is nontransforming when expressed in cells. If binding phosphorylated substrate protein to the membrane were critical, the two mutants would be expected to complement each other in trans to induce transformation. We found, however, that expression of the K290M mutant did not increase the transforming potential of the R171K mutant (not shown), arguing against such a model.

An important clue to $\mathrm{SH} 2$ domain function was obtained from the $\mathrm{SH} 2$ domain swap experiments. We showed that heterologous SH2 domains could complement the lack of the Abl SH2 domain and, more importantly, that cells infected with mutants bearing heterologous $\mathrm{SH} 2$ domains displayed different patterns of tyrosine-phosphorylated proteins. In fact, the pattern of phosphoproteins correlated roughly with the known specificities of the different $\mathrm{SH} 2$ domains; i.e., the phosphorylation of proteins with high affinity for a particular $\mathrm{SH} 2$ domain was enhanced in cells infected with the $\mathrm{Abl}$ mutants bearing that $\mathrm{SH} 2$ domain. This was true even if the catalytic domain was swapped for that of Src, suggesting that much of the substrate specificity of the nonreceptor tyrosine kinases might be conferred by the $\mathrm{SH} 2$ domain and not the catalytic domain.

How does the SH2 domain affect substrate specificity? We propose that what is actually being modulated is not substrate specificity per se, but the prolonged phosphorylation of proteins that bind to the $\mathrm{SH} 2$ domain. Unlike the case for serine-threonine kinases, there is little in vitro evidence for substrate specificity for the tyrosine kinases, and it is possible that they can phosphorylate virtually any phosphotyrosine residue that is accessible. At the same time, cellular tyrosine phosphatase activities are very high, so most proteins are rapidly dephosphorylated in vivo. If the site that is phosphorylated had high affinity for the $\mathrm{SH} 2$ domain, however, it could tightly bind to it; once bound, it would probably be protected from phosphatases, since several studies have shown that binding to $\mathrm{SH} 2$ domains can protect phosphotyrosine residues from dephosphorylation in vitro $(3,44)$. Furthermore, if the protein is tethered to the kinase via the $\mathrm{SH} 2$ domain, the local concentration of the catalytic domain would be extremely high and it is likely that the protein would be repeatedly phosphorylated on multiple sites. Both of these mechanisms (protection from dephosphorylation and repeated phosphorylation) are likely to play a role, since addition of vanadate, a tyrosine phosphatase inhibitor, to the culture media of cells infected with an SH2 domain-deleted mutant increased tyrosine phosphorylation on cell proteins, but not to the level seen if the $\mathrm{SH} 2$ domain was present (not shown).

The model outlined above is consistent with our observation that the SH2 domain is largely position independent when $\mathrm{N}$ terminal to the catalytic domain, because it is unlikely that precise positioning would be required to bind to proteins phosphorylated by the catalytic domain, given its high local concentration. Furthermore, such a model would predict that $\mathrm{SH} 2$ domains would function independently and additively, consistent with our data from mutants containing both the Abl and GAP SH2 domains. It is possible that the SH2 domains of other families of nonreceptor tyrosine kinases perform a similar role, since $\mathrm{SH} 2$ domain mutations in v-Fps and $\mathrm{v}-\mathrm{Src}$ can drastically affect transforming activity and substrate phosphorylation $(18,43,45,55)$. However, as discussed below, there are also important differences, at least in the case of Src, in which the $\mathrm{SH} 2$ domain also has an inhibitory role.

The model described above implies that the stoichiometry of tyrosine-phosphorylated substrates to Abl protein itself should be roughly equimolar, which is consistent with the levels of proteins seen in antiphosphotyrosine immunoblots. Therefore, as is the case with the receptor class of tyrosine kinases, it appears that the Abl nonreceptor kinase signals via stoichiometric complexes of proteins without signal amplification. This picture is very different from the traditional paradigm, taken from serine-threonine kinases, that kinases amplify signals by phosphorylating many substrate proteins when activated.

A further implication of the $\mathrm{SH} 2$ domain swap experiments is that many sets of tyrosine-phosphorylated proteins can induce transformation. The specificities of the $\mathrm{SH} 2$ domains used in these experiments, and thus the spectrum of proteins that would be phosphorylated in infected cells, are quite different, yet all of the constructs have considerable transforming activity. It is possible that there are common substrates that are relatively $\mathrm{SH} 2$ domain independent; in fact, all of the transforming mutants examined increase the phosphorylation of a protein of approximately $85 \mathrm{kDa}$ (Fig. 4A and 5A), which does not efficiently coimmunoprecipitate with $\mathrm{Abl}$ and thus is probably not bound via the $\mathrm{SH} 2$ domain. It is likely, however, that there is no one critical substrate for transformation and that many combinations of tyrosine-phosphorylated proteins 
can lead to growth. An analogy could be made to the growth factor receptors, which contain the binding sites for many $\mathrm{SH} 2$ domain-containing proteins; binding of several different proteins individually or in combination can be sufficient to signal DNA synthesis (53).

The models proposed above for $\mathrm{SH} 2$ and $\mathrm{SH} 3$ domain function in $\mathrm{Abl}$ are different in several respects from the functions proposed for these domains in the closely related Src family of nonreceptor tyrosine kinases (see reference 6 for a review). In these proteins, the $\mathrm{SH} 2$ domain has a largely inhibitory role on the activity of c-Src, since it interacts with a regulatory phosphotyrosine ( $\mathrm{Y}-527$ in $\mathrm{Src}$ ) that holds the c-Src protein in an inactive conformation. The c-Abl protein has no Y-527 equivalent and no detectable tyrosine phosphorylation in vivo (38), so such an inhibitory role for the $\mathrm{SH} 2$ domain is implausible. In Src, the positive role for the $\mathrm{SH} 2$ domain in transformation is apparently less important; although $\mathrm{SH} 2$ domain mutations can alter and weaken the transformed phenotype, mutants in which the $\mathrm{SH} 2$ domain has been completely deleted have been reported to be highly transforming (47). The SH3 domain in Src, like that in $\mathrm{Abl}$, is thought to have an inhibitory role, but unlike the case of Abl, Src SH3 domain mutants have elevated in vitro kinase activity (17). When c-Src is expressed in Schizosaccharomyces pombe, the $\mathrm{SH} 3$ domain cooperates with the $\mathrm{SH} 2$ domain to mediate binding to the regulatory C-terminal phosphotyrosine (51). These results indicate that in Src, the $\mathrm{SH} 3$ domain functions in cis, which our data suggest is not the case for Abl. These differences highlight how diversity of activity and regulation can evolve from very similar combinations of simple modular units.

\section{ACKNOWLEDGMENTS}

We thank R. Ren for critically reading the manuscript and M. Scott, W. Sha, T. Fujita, and other members of the laboratory for many helpful suggestions. We are also grateful to T. Miller for advice about quantitative kinase assays, P. Jackson for the K290M mutant, and S. Nagata for the human elongation factor $1 \alpha$ expression vector.

This work was supported by PHS grants CA 08875 to B.J.M. and CA 51462 to D.B.

\section{REFERENCES}

1. Alexandropoulos, K., R. Ren, W. Pear, P. Cicchetti, and D. Baltimore. Unpublished data.

1a.Anderson, D., C. A. Koch, L. Grey, C. Ellis, M. F. Moran, and T. Pawson. 1990. Binding of $\mathrm{SH} 2$ domains of phospholipase $\mathrm{C}_{\gamma} 1$, GAP, and src to activated growth factor receptors. Science 250: 979-982.

2. Ben-Neriah, Y., A. Bernards, M. Paskind, G. Q. Daley, and D. Baltimore. 1986. Alternative 5' exons in c- $a b l$ mRNA. Cell 44:577586.

3. Birge, R. B., J. E. Fajardo, B. J. Mayer, and H. Hanafusa. 1992. Tyrosine phosphorylated epidermal growth factor receptor and cellular p130 provide high affinity binding substrates to analyze crk-phosphotyrosine-dependent interactions in vitro. J. Biol. Chem. 267:10588-10595.

4. Cicchetti, P., B. J. Mayer, G. Thiel, and D. Baltimore. 1992. Identification of a protein that binds to the $\mathrm{SH} 3$ region of $\mathrm{Abl}$ and is similar to Bcr and GAP-rho. Science 257:803-806.

5. Cooper, J. A. 1990. The src family of protein-tyrosine kinases, p. 85-113. In B. Kemp and P. F. Alewood (ed.), Peptides and protein phosphorylation. CRC Press, Boca Raton, Fla.

6. Cooper, J. A., and B. Howell. 1993. The when and how of Src regulation. Cell 73:1051-1054.

7. Daley, G. Q., R. A. Van Etten, and D. Baltimore. 1990. Induction of chronic myelogenous leukemia in mice by the $\mathrm{P} 210 \mathrm{bcr} / \mathrm{abl}$ gene of the Philadelphia chromosome. Science 247:824-830.

8. Escobedo, J. A., S. Navankasattusas, W. M. Kavanaugh, D. Milfay, V. A. Fried, and L. T. Williams. 1991. cDNA cloning of a novel 85 $\mathrm{kd}$ protein that has $\mathrm{SH} 2$ domains and regulates binding of PI3-kinase to the PDGF $\beta$-receptor. Cell 65:75-82.

9. Foulkes, J. G., M. Chow, C. Gorka, A. R. Frackelton, Jr., and D. Baltimore. 1985. Purification and characterization of a proteintyrosine kinase encoded by the Abelson murine leukemia virus. J. Biol. Chem. 260:8070-8077.

10. Franz, W. M., P. Berger, and J. Y. J. Wang. 1989. Deletion of an $\mathrm{N}$-terminal regulatory domain of the c- $a b l$ tyrosine kinase activates its oncogenic potential. EMBO J. 8:137-147.

11. Glenney, J. R., L. Zokas, and M. P. Kamps. 1988. Monoclonal antibodies to phosphotyrosine. J. Immunol. Methods 109:277-285.

12. Goff, S. P., E. Gilboa, O. N. Witte, and D. Baltimore. 1980. Structure of the Abelson murine leukemia virus genome and the homologous cellular gene: studies with cloned viral DNA. Cell 22:777-785.

13. Hanks, S. K., A. M. Quinn, and T. Hunter. 1988. The protein kinase family: conserved features and deduced phylogeny of the catalytic domains. Science 241:42-52.

14. Hunter, T. 1991. Cooperation between oncogenes. Cell 64:249270.

15. Jackson, P., and D. Baltimore. 1989. N-terminal mutations activate the leukemogenic potential of the myristoylated form of c-abl. EMBO J. 8:449-456.

15a.Jackson, P., and D. Baltimore. Unpublished data.

16. Jackson, P. K., M. Paskind, and D. Baltimore. 1993. Mutation of a phenylalanine conserved in SH3-containing tyrosine kinases activates the transforming ability of c-Abl. Oncogene 8:1943-1956.

17. Kato, J.-Y., T. Takeya, C. Grandori, H. Iba, J. B. Levy, and H. Hanafusa. 1986. Amino acid substitutions sufficient to convert the nontransforming $\mathrm{p} 60^{\mathrm{c}-\mathrm{s} r \mathrm{c}}$ protein to a transforming protein. Mol. Cell. Biol. 6:4155-4160.

18. Koch, C. A., M. F. Moran, I. Sadowski, and T. Pawson. 1989. The common src homology region 2 domain of cytoplasmic signaling proteins is a positive effector of $\mathrm{v}-f p s$ tyrosine kinase function. Mol. Cell. Biol. 9:4131-4140.

19. Konopka, J. B., R. L. Davis, S. M. Watanabe, A. S. Ponticelli, L. Schiff-Maker, N. Rosenberg, and O. N. Witte. 1984. Only sitedirected antibodies reactive with the highly conserved $s r c$-homologous region of the $\mathrm{v}-a b l$ protein neutralize kinase activity. $\mathrm{J}$. Virol. 51:223-232.

20. Margolis, B., N. Li, A. Koch, M. Mohammadi, D. R. Hurwitz, A. Zilberstein, A. Ullrich, T. Pawson, and J. Schlessinger. 1990. The tyrosine-phosphorylated carboxyterminus of the EGF receptor is a binding site for GAP and PLC- $\gamma$. EMBO J. 9:4375-4380.

21. Martinez, R., B. Mathey-Prevot, A. Bernards, and D. Baltimore. 1987. Neuronal pp60 $0^{\text {c-src }}$ contains a six-amino acid insertion relative to its non-neuronal counterpart. Science 237:411-415.

22. Matsuda, M., B. J. Mayer, Y. Fukui, and H. Hanafusa. 1990. Binding of transforming protein, $\mathrm{P} 47^{\text {gag-crk }}$, to a broad range of phosphotyrosine-containing proteins. Science 248:1537-1539.

23. Matsuda, M., B. J. Mayer, and H. Hanafusa. 1991. Identification of domains of the v-crk oncogene product sufficient for association with phosphotyrosine-containing proteins. Mol. Cell. Biol. 11: 1607-1613.

24. Mayer, B. J., and D. Baltimore. 1993. Signalling through SH2 and SH3 domains. Trends Cell Biol. 3:8-13.

24a.Mayer, B. J., and D. Baltimore. Unpublished data.

25. Mayer, B. J., P. K. Jackson, and D. Baltimore. 1991. The noncatalytic $s r c$ homology region 2 segment of $a b l$ tyrosine kinase binds to tyrosine-phosphorylated cellular proteins with high affinity. Proc. Natl. Acad. Sci. USA 88:627-631.

26. Mayer, B. J., P. K. Jackson, R. A. Van Etten, and D. Baltimore. 1992. Point mutations in the $a b l \mathrm{SH} 2$ domain coordinately impair phosphotyrosine binding in vitro and transforming activity in vivo. Mol. Cell. Biol. 12:609-618.

27. McCormick, F. 1993. How receptors turn ras on. Nature (London) 363:15-16

28. Mes-Masson, A.-M., J. McLaughlin, G. Q. Daley, M. Paskind, and O. N. Witte. 1986. Overlapping cDNA clones define the complete coding region for the $\mathrm{P} 210^{\mathrm{c}-a b l}$ gene product associated with chronic myelogenous leukemia cells containing the Philadelphia chromosome. Proc. Natl. Acad. Sci. USA 83:9768-9772.

29. Mizushima, S., and S. Nagata. 1990. pEF-BOS, a powerful 
mammalian expression vector. Nucleic Acids Res. 18:5322.

30. Moran, M. F., C. A. Koch, D. Anderson, C. Ellis, L. England, G. S. Martin, and T. Pawson. 1990. Src homology region 2 domains direct protein-protein interactions in signal transduction. Proc. Natl. Acad. Sci. USA 87:8622-8626.

31. Muller, A. J., A. M. Pendergast, K. Parmar, M. H. Havlik, N. Rosenberg, and O. N. Witte. 1993. En bloc substitution of the Src homology region 2 domain activates the transforming potential of the c-Abl protein-tyrosine kinase. Proc. Natl. Acad. Sci. USA 90:3457-3461.

32. Muller, A. J., J. C. Young, A. M. Pendergast, M. Pondel, N. Landau, D. R. Littman, and O. N. Witte. 1991. $B C R$ first exon sequences specifically activate the $B C R / A B L$ tyrosine kinase oncogene of Philadelphia chromosome-positive human leukemias. Mol. Cell. Biol. 11:1785-1792.

33. Panayotou, G., and M. D. Waterfield. 1993. The assembly of signalling complexes by receptor tyrosine kinases. Bioessays 15: 171-177.

34. Pawson, T., and G. Gish. 1992. SH2 and SH3 domains: from structure to function. Cell 71:359-362.

35. Pazin, M. J., and L. T. Williams. 1992. Triggering signalling cascades by receptor tyrosine kinases. Trends Biochem. Sci. 17: 374-378.

36. Pear, W. S., G. P. Nolan, M. L. Scott, and D. Baltimore. 1993. Production of high-titer helper-free retroviruses by transient transfection. Proc. Natl. Acad. Sci. USA 90:8392-8396.

37. Pendergast, A. M., A. J. Muller, M. H. Havlik, R. Clark, F. McCormick, and O. N. Witte. 1991. Evidence for regulation of the human ABL tyrosine kinase by a cellular inhibitor. Proc. Natl. Acad. Sci. USA 88:5927-5931.

38. Ponticelli, A. S., C. A. Whitlock, N. Rosenberg, and O. N. Witte. 1982. In vivo tyrosine phosphorylations of the abelson virus transforming protein are absent in its normal cellular homolog. Cell 29:953-960.

39. Potts, W. M., A. B. Reynolds, T. J. Lansing, and J. T. Parsons. 1988. Activation of pp60 $0^{\mathrm{c}-s r c}$ transforming potential by mutations altering the structure of an amino terminal domain containing residues 90-95. Oncogene Res. 3:343-355.

40. Reichman, C. T., B. J. Mayer, S. Keshav, and H. Hanafusa. 1992. The product of the cellular $c r k$ gene consists primarily of $\mathrm{SH} 2$ and SH3 regions. Cell Growth Differ. 3:451-460.

40a.Ren, R., K. Alexandropoulos, and D. Baltimore. Unpublished data.

41. Ren, R., B. J. Mayer, P. Cicchetti, and D. Baltimore. 1993. Identification of a 10-amino acid proline-rich SH3 binding site. Science 259:1157-1161.

42. Renshaw, M. W., E. T. Kipreos, M. R. Albrecht, and J. Y. J. Wang. 1992. Oncogenic v-Abl tyrosine kinase can inhibit or stimulate growth, depending on the cell context. EMBO J. 11:3941-3951.

43. Reynolds, A. B., S. B. Kanner, H.-C. R. Wang, and J. T. Parsons.
1989. Stable association of activated pp60 $60^{s c}$ with two tyrosinephosphorylated cellular proteins. Mol. Cell. Biol. 9:3951-3958.

44. Rotin, D., B. Margolis, M. Mohammadi, R. J. Daly, G. Daum, N. Li, E. H. Fischer, W. H. Burgess, A. Ullrich, and J. Schlessinger. 1992. SH2 domains prevent tyrosine dephosphorylation of the EGF receptor: identification of Tyr992 as the high-affinity binding site for SH2 domains of phospholipase C $\gamma$. EMBO J. 11:559-567.

45. Sadowski, I., J. C. Stone, and T. Pawson. 1986. A noncatalytic domain conserved among cytoplasmic protein-tyrosine kinases modifies the kinase function and transforming activity of Fujinami sarcoma virus P130 gag-fps. Mol. Cell. Biol. 6:4396-4408.

46. Schlessinger, J., and A. Ullrich. 1992. Growth factor signaling by receptor tyrosine kinases. Neuron 9:383-391.

47. Seidel-Dugan, C., B. E. Meyer, S. M. Thomas, and J. S. Brugge. 1992. Effects of SH2 and SH3 deletions on the functional activities of wild-type and transforming variants of c-Src. Mol. Cell. Biol. 12:1835-1845.

48. Shtivelman, E., B. Lifshitz, R. P. Gale, and E. Canaani. 1985. Fused transcript of $a b l$ and $b c r$ genes in chronic myelogenous leukaemia. Nature (London) 315:550-554.

49. Smith, D. B., and K. S. Johnson. 1988. Single-step purification of polypeptides expressed in Escherichia coli as fusions with glutathione S-transferase. Gene 67:31-40.

50. Songyang, Z., S. E. Shoelson, M. Chaudhuri, G. Gish, T. Pawson, W. G. Haser, F. King, T. Roberts, S. Ratnofsky, R. J. Lechleider, B. G. Neel, R. B. Birge, J. E. Fajardo, M. M. Chou, H. Hanafusa, B. Shaffhausen, and L. C. Cantley. 1993. SH2 domains recognize specific phosphopeptide sequences. Cell 72:767-778.

51. Superti-Furga, G., S. Fumagalli, M. Koegl, S. A. Courtneidge, and G. Draetta. 1993. Csk inhibition of c-Src activity requires both the SH2 and SH3 domains of Src. EMBO J. 12:2625-2634.

52. Trahey, M., G. Wong, R. Halenbeck, B. Rubinfeld, G. A. Martin, M. Ladner, C. M. Long, W. J. Crosier, K. Watt, K. Koths, and F. McCormick. 1988. Molecular cloning of two types of GAP cDNA from human placenta. Science 242:1697-1700.

53. Valius, M., and A. Kazlauskas. 1993. Phospholipase C- $\gamma 1$ and phosphatidylinositol 3 kinase are the downstream mediators of the PDGF receptor's mitogenic signal. Cell 73:321-334.

53a.Van Etten, R. Personal communication.

54. Van Etten, R. A., P. Jackson, and D. Baltimore. 1989. The mouse type IV c-abl gene product is a nuclear protein, and activation of transforming ability is associated with cytoplasmic localization. Cell 58:669-678.

55. Wang, H.-C., and J. T. Parsons. 1989. Deletions and insertions within an amino-terminal domain of pp60 ${ }^{\mathrm{v}-s r}$ inactivate transformation and modulate membrane stability. J. Virol. 63:291-302.

56. Wang, J. Y. J. 1993. Abl tyrosine kinase in signal transduction and cell-cycle regulation. Curr. Opin. Genet. Dev. 3:35-43. 